\title{
Puborectalis Muscle Involvement on Magnetic Resonance Imaging in Complex Fistula: A New Perspective on Diagnosis and Treatment
}

\author{
Hong Yoon Jeong, Seok Gyu Song, Woo Jung Nam, Jong Kyun Lee \\ Department of Surgery, Seoul Song Do Hospital, Seoul, Korea
}

Purpose: According to recent studies, magnetic resonance imaging (MRI) assessment of complex fistulas provides a significant benefit compared to fistulography, computed tomography, and ultrasonography. The aim of this study was to describe the accuracy of MRI and the importance of identifying puborectalis muscle involvement on MRI in patients with complex fistula.

Methods: All patients who were clinically diagnosed with 'complex' or showed multiple fistula tracts underwent fistula MRI. Eligible patients were consecutive patients who underwent fistula MRI between September 2018 and September 2019 at our hospital.

Results: A total of 83 patients ( 74 males, 9 females; 116 tracts) were included in this study. The sensitivity and specificity of MRI in diagnosing fistula tracts were $94.8 \%$ and $98.2 \%$, respectively. The sensitivity and specificity in identifying internal opening were $93.9 \%$ and $97.3 \%$, respectively. Of the 35 patients with puborectalis muscle involvement in the MRI, 31 images of suprasphincteric-type patients on the Park's classification were classified. The patients of puborectalis involvement were divided into 2 groups according to the surgical procedure that was performed. There were 12 sphincter-saving procedures and 19 sphincter division procedures performed. Recurrence was seen in 2 patients in the sphincter-saving procedure group, while no case was seen in the sphincter division procedure group. Five complications were found in the sphincter division procedure group, of which 2 reported incontinence.

Conclusion: Fistula MRI is a highly accurate examination for evaluating complex fistulas, and the puborectalis muscle involvement findings are very important for diagnosis and treatment.

Keywords: Complex fistula; Fistula magnetic resonance imaging; Puborectalis muscle involvement

\section{INTRODUCTION}

The first reports on the accuracy of magnetic resonance imaging (MRI) for the detection and classification of fistulas were published in 1992 and 1994 [1, 2]. Since then, many articles have reported high accuracy values for MRI in the detection of fistula

Received: Jul 2, 2020 - Revised: Aug 20, 2020 - Accepted: Aug 26, 2020 Correspondence to: Hong Yoon Jeong, M.D.

Department of Surgery, Seoul Song Do Hospital, 72 Dasan-ro, Jung-gu, Seoul 04597, Korea

Tel: +82-2-2250-7368, Fax: +82-2-2233-8528

E-mail: vishnujin84@gmail.com

ORCID: https://orcid.org/0000-0002-2385-6069

(C) 2021 The Korean Society of Coloproctology

This is an open-access article distributed under the terms of the Creative Commons Attribution NonCommercial License (https://creativecommons.org/licenses/by-nc/4.0) which permits unrestricted noncommercial use, distribution, and reproduction in any medium, provided the original work is properly cited. tracts and secondary extensions [3, 4]. Moreover, MRI has been shown to alter the surgical approach and influence surgical outcomes [5-7]. Most importantly, MRI-guided surgery can significantly reduce postoperative recurrence in complex cases by $75 \%$ [7]. Agreement for preoperative assessment of perianal fistula using MRI between experts and novices is good, while intraobserver agreement is also acceptable after a period of directed education [8]. Therefore, MRI is identified as the modality of choice for the preoperative evaluation of complex or recurrent fistula [5].

The Standard Practice Task Force, by the American Society of Colon and Rectal Surgeons (ASCRS), classifies anal fistulas as 'simple' and 'complex.' The latter category identifies the increased risk of incontinence after surgery [9]. Parks et al. [10] emphasized the importance of an adequate anorectal angle to maintain continence. The anorectal angle is created by the anterior pull of the puborectalis sling at the level of the anorectal junction. Puborec- 
talis muscle contraction was an independent variable with the strongest correlation to the clinical severity of incontinence [11]. MRI not only shows supralevator extension of the fistula and a rectal opening with high accuracy but also precisely shows puborectalis muscle involvement of the fistula [12]. Therefore, we believe that it is essential to confirm the presence or absence of puborectalis muscle involvement on MRI before operation.

According to recent studies, MRI assessment of complex fistulas provides a significant benefit compared to fistulography, computed tomography $(\mathrm{CT})$, and ultrasonography $[5,13]$. Inevitably, the demand for MRI techniques in the treatment of complex fistula will increase. The aim of this study was to describe the accuracy of MRI and the importance of identifying puborectalis muscle involvement on MRI in patients with complex fistula.

\section{METHODS}

\section{Patients}

This study was approved by the Institutional Review Boards of the participating institutions (No. 2020-004). The requirement for informed consent of patients was waived because of the retrospective nature of the study. Patients referred to the outpatient clinic for anal fistula were assessed for eligibility. The attending surgeon identified potential participants and classified the anal fistula as 'complex' or 'simple' according to the ASCRS fistula guidelines [14]. All patients who were clinically diagnosed with 'complex' or showed multiple fistula tracts underwent fistula MRI. Eligible patients were consecutive patients who underwent fistula MRI between September 2018 and September 2019 at the Seoul Songdo Hospital. Demographic data, medical history, as well as surgical and follow-up details of the patients were recorded. All patients underwent acid-fast bacterium stain of anal discharge and punch biopsies at the external opening sites to exclude tuberculosis or Crohn fistula. All patients underwent anal manometry and pudendal nerve terminal motor latency testing for evaluation of anorectal physiology. Patients without acute anal sepsis (such as abscess) underwent MRI a week before surgery. In the case of acute anal abscess on ultrasound, MRI was performed after adequate drainage for 4 weeks.

\section{Magnetic resonance imaging technique}

All MRI examinations were performed in a supine position at rest using a 1.5 T magnet (Intera 1.5 T, Philips, Amsterdam, Netherlands) with a 4-channel phased-array sense body coil. We obtained T2-weighted turbo spin echo (TSE) sagittal, anal axial, anal coronal, and short tau inversion recovery anal axial images with the following imaging parameters: TR/TE effect 600 to 780/20; flip angle, $90^{\circ}$; field of view, 225 to $400 \mathrm{~mm}$; slice thickness, $3 \mathrm{~mm}$ interleaved; imaging matrix, $512 \times 512$. After $7.5 \mathrm{~mL}$ of contrast material (Gadovist, Bayer Schering Pharma AG, Germany) was injected, fat-saturated T1-weighted TSE magnetic resonance (MR) images (sagittal, anal axial, and anal coronal) were obtained.
After the MRI procedure, the source images were electronically transferred to a picture archiving and communication system (Piview STAR, INFINITT Technology, Seoul, Korea).

One experienced radiologist evaluated the MR images using an Easy Vision Workstation (Philips). To characterize an anal fistula, the radiologist analyzed images and described the following: (1) internal opening site, (2) external opening site, (3) existence of rectal opening, (4) demonstration of hidden areas of sepsis and secondary extensions, (5) coexisting fistulas, (6) detailed description of the pathway of the fistulous tract and its relationship with the puborectalis muscle, and (7) classification of the fistula type.

\section{Magnetic resonance imaging accuracy}

Intraoperatively, the internal opening was identified by injecting methylene blue solution through the external opening after the intraoperative rectal examination. The findings of clinical examination and MRI finding were correlated with the intraoperative findings. During surgery, the details of the openings and the tracts were carefully noted and then compared to the MRI findings. Any findings missed or misdiagnosed by MRI were carefully noted. These inaccuracies of MRI were then used to calculate sensitivity and specificity of the MRI.

\section{Puborectalis muscle involvement}

The MRI of all patients was described by detailed description of the pathway of the fistulous tract and its relationship with the puborectalis muscle by the radiologist. Puborectalis muscle involvement was defined as the case where the fistula tract passed the puborectalis muscle or the end of the fistula was located, or when the associated abscess invaded the puborectalis muscle. The MRI findings of patients with puborectalis muscle involvement in suprasphincteric type on Park's classification were analyzed. The MRI findings of a total of 31 patients appear as follows: the tract was inflamed into the levator ani muscle (including puborectalis muscle) and then stretched to the supralevator space and ischioanal space (Fig. 1A); the tract passed through the levator ani muscle (including puborectalis muscle) and into the ischioanal space (Fig. 1B); the tract passed through the puborectalis muscle and into the ischioanal space (Fig. 1C); the fistula tract was inflamed into the levator ani muscle (including puborectalis muscle) and was confined to it (Fig. 1D); and the fistula tract was inflamed into the puborectalis muscle and was confined to it (Fig. 1E).

\section{Surgical method and outcome}

We analyzed the surgical outcomes of patients with puborectalis muscle involvement findings on MRI retrospectively. To match the severity of the fistula extrasphincteric type excluded from the Park's classification, 31 patients with puborectalis muscle involvement in suprasphincteric type were enrolled. The enrolled patients were then divided into 2 groups according to the surgical procedure, the first group underwent the sphincter-saving procedure and the second underwent the sphincter division procedure. 


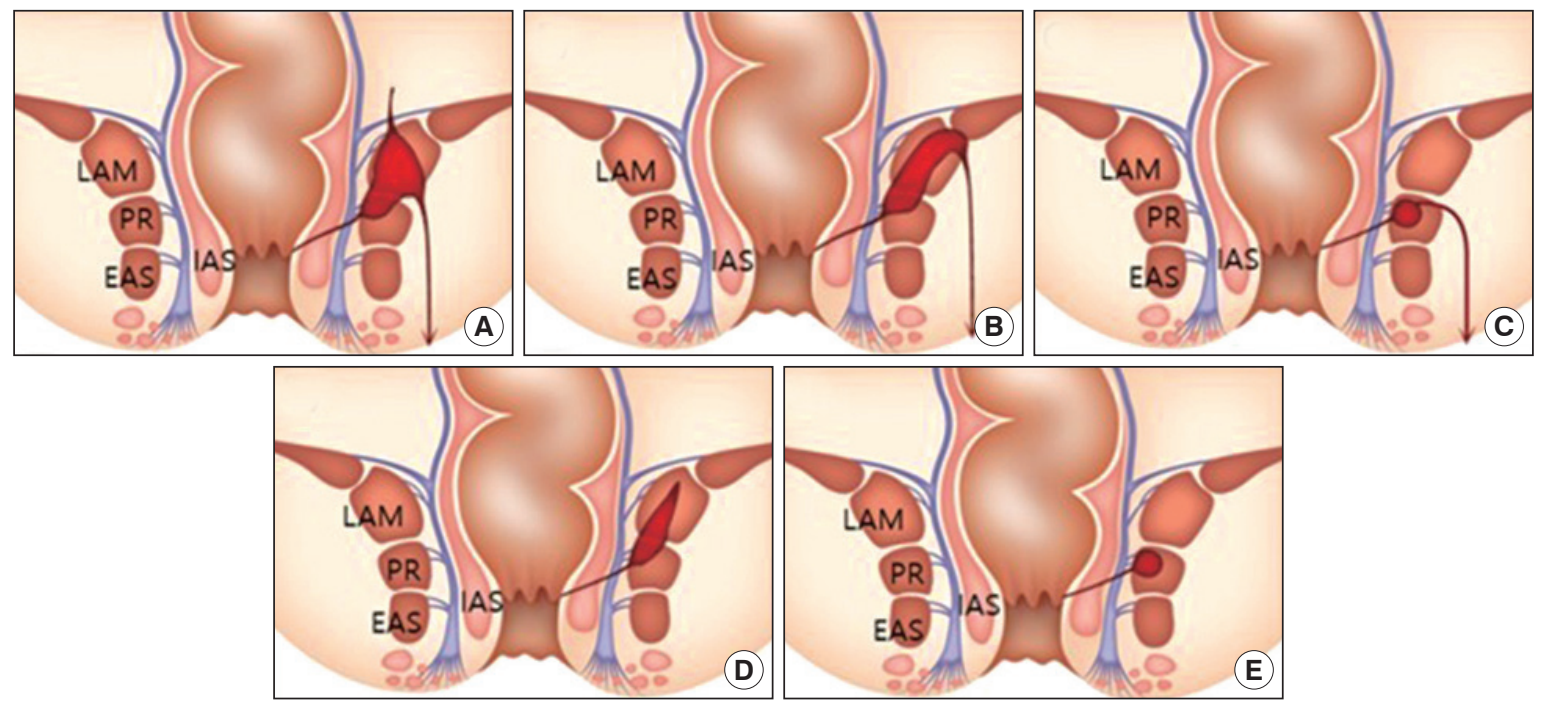

Fig. 1. The magnetic resonance imaging findings of patients with puborectalis muscle involvement in suprasphincteric type. Prevalence of type (total 31 tracts) is (A) 1 (3.2\%), (B) 5 (16.1\%), (C) 14 (45.2\%), (D) 3 (9.7\%), and (E) 8 (28.8\%). LAM, levator ani muscle; PR, puborectalis muscle; EAS, external anal sphincter; IAS, internal anal sphincter.

For the sphincter-saving procedure, LIFT (ligation of intersphincteric fistula tract) and ALMC (anal duct ligation and muscle closure), the original surgical method of our institution, were used. Also, the sphincter division procedure was performed using the seton procedure. All surgeries were performed by 5 surgeons with over 10 years of experience. Recurrence and complications were diagnosed as clinical symptoms and examinations in the outpatient clinic.

\section{Statistical analysis}

Statistical analysis performed using IBM SPSS Statistics ver. 22.0 (IBM Corp., Armonk, NY, USA). Quantitative data were expressed as medians and ranges. Statistical analysis was performed using the paired t-test for paired data. A P-value of $<0.05$ was considered statistically significant.

\section{RESULTS}

A total of 83 patients (74 males, 9 females; 116 tracts) were included in this study. The tract was missed by MRI scan in 4 patients and wrongly reported in 2 patients. The internal opening was missed in 5 and wrongly reported in 3 patients. The sensitivity and specificity of MRI in diagnosing fistula tracts were $94.8 \%$ and $98.2 \%$, respectively. The sensitivity and specificity in identifying internal opening were $93.9 \%$ and $97.3 \%$, respectively (Table 1 ).

There were no differences in age, sex, and body mass index (BMI) between the 2 groups. In the previous operation, there were $16(45.7 \%)$ statistically significant fistula operations in the puborectalis involvement group (Table 2). According to the classification SPTF classification, there were 14 patients with simple
Table 1. Accuracy of magnetic resonance imaging in complex fistula patients

\begin{tabular}{lcc}
\hline Variable & Tract $(\mathrm{n}=116)$ & Internal opening $(\mathrm{n}=115)$ \\
\hline Accurately delineated & $110(94.8)$ & $108(93.9)$ \\
Missed & $4(3.4)$ & $5(4.3)$ \\
Misdiagnosed & $2(1.7)$ & $3(2.6)$ \\
Sensitivity & $110 / 116(94.8)$ & $108 / 115(93.9)$ \\
Specificity & $110 / 112(98.2)$ & $108 / 111(97.3)$ \\
\hline
\end{tabular}

Values are presented as number (\%).

fistula and 69 patients with complex fistula (Table 2). As per St. James Hospital classification, the features were James type 1 in 6 , type 2 in 8 , type 3 in 18, type 4 in 15, and type 5 in 36 . In addition, according to the Park's classification, 15 were in intersphincteric type, 30 were in transsphincteric type, 34 were in suprasphincteric type, and 4 were in extrasphincteric type (Table 2). The clinical examination revealed $15(18.1 \%)$ patients were recurrent and 2 (2.4\%) were anterior in the female population.

Table 3 compares the characteristics of fistula between the 35 patients with puborectalis muscle involvement and other patients. In the puborectalis involvement group, the horseshoe tracts were 23 in number and were statistically significantly higher than the non-puborectalis involvement group. Supralevator extension was found in greater numbers in the puborectalis involvement group, while associated abscesses and multiple internal openings were found in greater numbers in the non-puborectalis involvement group, but there was no statistical significance in these findings (Table 3). 
Table 2. Demographics and clinical characteristics of patients

\begin{tabular}{|c|c|c|c|}
\hline Characteristic & $\begin{array}{l}\text { Puborectalis } \\
\text { involvement } \\
\quad(n=35)\end{array}$ & $\begin{array}{l}\text { Non-puborectalis } \\
\text { involvement } \\
(n=48)\end{array}$ & P-value \\
\hline Age (yr) & $46.86 \pm 12.12$ & $42.44 \pm 14.35$ & 0.144 \\
\hline Sex & & & 0.570 \\
\hline Male & $32(91.4)$ & $42(87.5)$ & \\
\hline Female & $3(8.6)$ & $6(12.5)$ & \\
\hline Body mass index $\left(\mathrm{kg} / \mathrm{m}^{2}\right)$ & $25.62 \pm 4.71$ & $26.03 \pm 4.05$ & 0.670 \\
\hline \multicolumn{4}{|l|}{ Previous operation } \\
\hline Fistula operation & $16(45.7)$ & $9(18.8)$ & 0.015 \\
\hline Hemorrhoid operation & $1(2.9)$ & $7(14.6)$ & 0.074 \\
\hline Abscess operation & $22(62.9)$ & $34(70.8)$ & 0.483 \\
\hline \multicolumn{4}{|l|}{ SPTF classification } \\
\hline Simple & $0(0)$ & 14 (29.2) & $<0.001$ \\
\hline Complex & $35(100)$ & $34(70.8)$ & \\
\hline \multicolumn{4}{|c|}{ St. James Hospital classification } \\
\hline Grade 1 & $0(0)$ & $6(12.5)$ & $<0.001$ \\
\hline Grade 2 & $0(0)$ & $8(16.7)$ & \\
\hline Grade 3 & $0(0)$ & $18(37.5)$ & \\
\hline Grade 4 & $1(2.9)$ & $14(29.2)$ & \\
\hline Grade 5 & $34(97.1)$ & $2(4.2)$ & \\
\hline \multicolumn{4}{|l|}{ Park's classification } \\
\hline Intersphincteric type & $0(0)$ & $15(31.3)$ & $<0.001$ \\
\hline Transsphincteric type & $0(0)$ & $30(62.5)$ & \\
\hline Suprasphincteric type & $31(88.6)$ & $3(6.3)$ & \\
\hline Extrasphincteric type & $4(11.4)$ & $0(0)$ & \\
\hline \multicolumn{4}{|l|}{ Clinical examination } \\
\hline Recurrent & $9(25.7)$ & $6(12.5)$ & 0.153 \\
\hline Anterior in female & $0(0)$ & $2(4.2)$ & 0.222 \\
\hline
\end{tabular}

Values are presented as mean \pm standard deviation or number (\%). SPTF, Standard Practice Task Force.

Of the 35 patients with puborectalis muscle involvement in the MRI, 31 images of suprasphincteric-type patients on the Park's classification were classified and shown in Fig. 1. The most common form was where the tract passed through the puborectalis muscle and into the ischioanal space, which was observed in 14 cases. In addition, MRI findings and prevalence of various types of puborectalis muscle involvement are summarized in Fig. 1. The patients mentioned above were divided into 2 groups according to the surgical procedure that was performed. There were 12 sphincter-saving procedures and 19 sphincter division procedures performed (Table 4). When comparing the 2 groups, the BMI was statistically significantly higher in the group that underwent the sphincter division procedure. On the other hand, the length of hospital stay was longer in the sphincter-saving procedure group.
Table 3. Fistula characteristics of puborectalis muscle involvement on magnetic resonance imaging

\begin{tabular}{lccc}
\hline Characteristic & $\begin{array}{c}\text { Puborectalis } \\
\text { involvement }\end{array}$ & $\begin{array}{c}\text { Non-puborectalis } \\
\text { involvement }\end{array}$ & P-value \\
\hline No. of patients & $35(42.2)$ & $48(57.8)$ & - \\
Multiple tracts & 9 & 8 & 0.410 \\
Horseshoe tracts & 23 & 6 & $<0.050$ \\
Associated abscess & 10 & 15 & 0.814 \\
Supralevator extension & 5 & 1 & 0.078 \\
Multiple internal opening & 7 & 20 & 0.057 \\
\hline
\end{tabular}

Values are presented as number (\%) or number only.

Table 4. Surgical outcome of suprasphincteric fistula with puborectalis muscle involvement

\begin{tabular}{lccc}
\hline & $\begin{array}{c}\text { Sphincter saving } \\
\text { procedure }\end{array}$ & $\begin{array}{c}\text { Sphincter division } \\
\text { procedure }\end{array}$ & P-value \\
\hline No. of patients & 12 & 19 & - \\
Age (yr) & $45 \pm 13$ & $46 \pm 11$ & 0.853 \\
Sex, male:female & $10: 02$ & $18: 01$ & 0.296 \\
Body mass index $\left(\mathrm{kg} / \mathrm{m}^{2}\right)$ & $22.91 \pm 3.90$ & $26.42 \pm 4.49$ & $<0.050$ \\
Hospital day & $4.92 \pm 1.73$ & $3.84 \pm 1.30$ & 0.058 \\
Follow-up period (mon) & $4.17 \pm 1.40$ & $4.79 \pm 2.88$ & 0.492 \\
Recurrence & $2(16.7)$ & $0(0)$ & 0.142 \\
Complication & $2(16.7)$ & $5(26.3)$ & 0.435 \\
Incontinence & $0(0)$ & $2(10.5)$ & \\
Postoperative bleeding & $1(8.3)$ & $2(10.5)$ & \\
Delayed wound healing & $1(8.3)$ & $1(5.3)$ & \\
\hline
\end{tabular}

Values are presented as number only, mean \pm standard deviation, or number (\%).

Recurrence was seen in 2 patients in the sphincter-saving procedure group, while no case was seen in the sphincter division procedure group. One patient with associated abscess relapsed 4 weeks after the procedure, and another patient showed recurrence 5 weeks after the procedure. There were 2 complications in the sphincter-saving procedure group, but no incontinence was reported. Five complications were found in the sphincter division procedure group, of which 2 reported incontinence.

\section{DISCUSSION}

Perianal fistula is a frequent disorder that can cause great difficulties for patients and surgeons. Overall, $5 \%$ to $15 \%$ of anal fistula tracts have a complicated course, with secondary extensions outside the anal sphincter, often with horseshoe fistulas and ischiorectal or supralevator abscesses [15]. Therefore, to adopt the best surgical strategy and avoid recurrences, it is necessary to obtain precise radiologic information about the location of the fistula 
tract and the affected pelvic structures [5]. MRI is the most accurate imaging tool to define anal canal anatomy and anal fistulas $[16,17]$. Our study measured the diagnostic accuracy of MRI and the importance of puborectalis muscle involvement findings in patients with complex fistulas.

Studies in other countries have been actively conducted. The previous 3 studies from other countries reported the sensitivity and specificity of fistula MRI in transsphincteric type and extra/ suprasphincteric type $[16,18,19]$. The sensitivity of MRI for transsphincteric fistulas was reported as $50 \%, 76 \%$, and $90 \%$, with specificity being reported as $20 \%, 94 \%$, and $98 \%$. The sensitivity of extra/suprasphincteric fistulas was reported as $50 \%, 86 \%$, and $94 \%$, while specificity was reported as $90 \%, 97 \%$, and $98 \%[16,18$, 19]. Unfortunately, there are very few MRI studies of perianal fistula in South Korea. The reason for lack of study is not only the absence of specialized centers where the surgeons are familiar with anorectal anatomy and the different types of fistula, but there are also problems with medical insurance and high prices. In our study, the sensitivity of MRI was $94.8 \%$ and the specificity was 98.2\%. Garg et al. [12], affirmed that MRI had remarkably high sensitivity and specificity in predicting the number and location of fistula tracts as well as the position of the internal opening. The sensitivity and specificity in identifying the internal opening were $97.7 \%$ and $98.6 \%$, respectively [12]. Similarly, this study also showed a high sensitivity $(93.9 \%)$ and specificity $(97.3 \%)$ for finding the location of the internal opening. Through preliminary examination, diseases such as Crohn disease and tuberculosis were excluded, and high MRI accuracy was obtained by using endoanal coils in all patients.

In several studies, radiological evaluation of fistulas with MRI contributed significantly to the surgical management of the disease. Garg et al. [12] have reported that MRI added significant information to the surgical management in 229 patients with additional tract, horseshoe tract, supralevator extension, unsuspected abscess, and multiple internal openings. Using these parameters, they concluded that MRI added significant information to $46.7 \%$ of the surgeries. A relatively smaller study of 40 patients by Mullen et al. [20] has shown that MRI positively contributed to the surgical management of the patients. They concluded that the positive contribution of MRI could be as high as $85 \%$ if used in selected cases. Our study focused on the clinical significance of puborectalis muscle involvement findings in various parameters of fistula MRI before surgery.

There are 3 clinical implications of puborectalis muscle involvement in patients with complex fistula. First, the puborectalis muscle involvement is valuable as an indicator of complex fistula. In our study, we found that multiple tracts, supralevator extension, and horseshoe tracts were more common in patients with puborectalis muscle involvement findings. Horseshoe tracts were particularly present in relation to the direction of inflammation in the formation of the fistula tract. Shafik [21] had released a new concept that the puborectalis is not part of the levator ani and in- stead constitute an integral part of the external anal sphincter (EAS) muscle. They created a more complicated division of perianal and perirectal spaces for the dissection of pus and fistula tracts $[22,23]$ as part of painstaking dissections of the musculofascial septum derived from the terminations and decussations of the longitudinal anal muscle [24]. These findings were at variance with anatomical dissections demonstrating the discrete separation of the deep EAS component from the puborectalis bundle by $\mathrm{Fu}$ cini et al. [25] and by Fröhlich et al. [26]. These studies have shown puborectalis/EAS separation on CT and MRI with demonstrably separable origins and insertions in plastinated specimens of the adult pelvis [26]. Moreover, the puborectalis muscle is only one horseshoe-shaped muscle in the anorectal area. Thus, the formation of a complex fistula tract and abscess cavity occurs through the puborectalis muscle fascia. Therefore, it is important to approach the complex fistula if MRI shows the involvement of the puborectalis muscle.

Second, the puborectalis muscle involvement findings indicate a variety of clinical features and a customized surgical treatment plan should be established. In 1976, Parks et al. [27] reported all fistulas could be classified into 4 main groups and they suggested that the suprasphincteric fistula tract passes in the intersphincteric plane over the top of the puborectalis. However, in recent studies, puborectalis muscle involvement findings were observed through three-dimensional ultrasonography and MRI [28]. In the present study, 5 types of clinical manifestations were shown in the suprasphincteric fistula with puborectalis muscle involvement. For example, the findings extended to the supralevator and ischioanal spaces as well as a blind pouch was observed in the puborectalis and levator ani muscles. It is necessary to confirm the findings and patterns of puborectalis muscle involvement on MRI before surgery to avoid contact with the unpleasant broad dead space or supralevator extension during surgery.

Third, patients with puborectalis muscle involvement should undergo a sphincter-saving procedure. Studies have reported some degree of fecal incontinence in up to $73 \%$ of patients who underwent fistulotomy, according to the risk factors of the patients. These risk factors included preoperative incontinence, recurrent disease, female sex, complex fistula, and previous fistula surgery [29]. There is no clear knowledge concerning the division of any part of the anal canal during the treatment of perianal fistula. However, it is clear that puborectalis muscle contraction is the independent variable with the strongest correlation to the clinical severity of incontinence [11]. In the present study, there were 2 patients with incontinence complications; both showed these complications after the sphincter division procedure. Both patients were young men, and symptoms of incontinence were not severe and could be controlled by conservative treatment. The anterior EAS is shorter in females and the percentage of compromised muscles is high [30]. However, in our study, female incontinence complications were not seen due to the low participation of female patients. Studies in the literature are contradictory con- 
cerning the amount of sphincter muscle that can be safely divided in anal fistulas, with some reporting that the division of less than $30 \%$ of the EAS carries a minimal risk of postoperative fecal incontinence [31]. Conversely, Garcés-Albir et al. [32] reported that the division of the lower $66 \%$ of the EAS was associated with excellent rates of continence and healing in patients who lacked risk factors before surgery. Although the results are limited due to the small sample size, the surgical outcome of this study suggested that patients with puborectalis muscle involvement seen in an MRI should undergo a sphincter-saving procedure.

Our study does have some limitations. Firstly, all interpretations of the MRI scans were by a single radiologist, and therefore, interobserver variability could not be determined. Secondly, the operating surgeon was not blinded to MRI findings. Both of these factors were the sources of potential bias in this study. Thirdly, the decision of surgical procedure was determined by the operator's preference. BMI was significantly higher in sphincter division procedure because high BMI interfered with the surgical field of view. This was the source of selection bias in this study. In the future, a prospective study of large volumes will examine the relationship between puborectalis muscle involvement and surgical procedures.

To conclude, fistula MRI is a highly accurate examination for evaluating complex fistulas, and the puborectalis muscle involvement findings are very important for diagnosis and treatment planning for complex fistulas.

\section{CONFLICT OF INTEREST}

No potential conflict of interest relevant to this article was reported.

\section{REFERENCES}

1. Lunniss PJ, Armstrong P, Barker PG, Reznek RH, Phillips RK. Magnetic resonance imaging of anal fistulae. Lancet 1992;340:3946.

2. Lunniss PJ, Barker PG, Sultan AH, Armstrong P, Reznek RH, Bartram CI, et al. Magnetic resonance imaging of fistula-in-ano. Dis Colon Rectum 1994;37:708-18.

3. Beckingham IJ, Spencer JA, Ward J, Dyke GW, Adams C, Ambrose NS. Prospective evaluation of dynamic contrast enhanced magnetic resonance imaging in the evaluation of fistula in ano. $\mathrm{Br}$ J Surg 1996;83:1396-8.

4. Halligan S, Bartram CI. MR imaging of fistula in ano: are endoanal coils the gold standard? AJR Am J Roentgenol 1998;171:40712.

5. de Miguel Criado J, del Salto LG, Rivas PF, del Hoyo LF, Velasco LG, de las Vacas MI, et al. MR imaging evaluation of perianal fistulas: spectrum of imaging features. Radiographics 2012;32:17594.

6. Beets-Tan RG, Beets GL, van der Hoop AG, Kessels AG, Vliegen
RF, Baeten CG, et al. Preoperative MR imaging of anal fistulas: does it really help the surgeon? Radiology 2001;218:75-84.

7. Buchanan G, Halligan S, Williams A, Cohen CR, Tarroni D, Phillips RK, et al. Effect of MRI on clinical outcome of recurrent fistula-in-ano. Lancet 2002;360:1661-2.

8. Buchanan GN, Halligan S, Taylor S, Williams A, Cohen R, Bartram C. MRI of fistula in ano: inter- and intraobserver agreement and effects of directed education. AJR Am J Roentgenol 2004;183:135-40.

9. Whiteford MH, Kilkenny J 3rd, Hyman N, Buie WD, Cohen J, Orsay C, et al. Practice parameters for the treatment of perianal abscess and fistula-in-ano (revised). Dis Colon Rectum 2005;48: 1337-42.

10. Parks AG, Porter NH, Hardcastle J. The syndrome of the descending perineum. Proc R Soc Med 1966;59:477-82.

11. Fernández-Fraga X, Azpiroz F, Malagelada JR. Significance of pelvic floor muscles in anal incontinence. Gastroenterology 2002; 123:1441-50.

12. Garg P, Singh P, Kaur B. Magnetic resonance imaging (MRI): operative findings correlation in 229 fistula-in-ano patients. World J Surg 2017;41:1618-24.

13. Yousem DM, Fishman EK, Jones B. Crohn disease: perirectal and perianal findings at CT. Radiology 1988;167:331-4.

14. Vogel JD, Johnson EK, Morris AM, Paquette IM, Saclarides TJ, Feingold DL, et al. Clinical practice guideline for the management of anorectal abscess, fistula-in-ano, and rectovaginal fistula. Dis Colon Rectum 2016;59:1117-33.

15. Seow-Choen, Phillips RK. Insights gained from the management of problematical anal fistulae at St. Mark's Hospital, 1984-88. Br J Surg 1991;78:539-41.

16. Maier AG, Funovics MA, Kreuzer SH, Herbst F, Wunderlich M, Teleky BK, et al. Evaluation of perianal sepsis: comparison of anal endosonography and magnetic resonance imaging. J Magn Reson Imaging 2001;14:254-60.

17. Sahni VA, Ahmad R, Burling D. Which method is best for imaging of perianal fistula? Abdom Imaging 2008;33:26-30.

18. Buchanan GN, Halligan S, Bartram CI, Williams AB, Tarroni D, Cohen CR. Clinical examination, endosonography, and MR imaging in preoperative assessment of fistula in ano: comparison with outcome-based reference standard. Radiology 2004;233:67481.

19. Gustafsson UM, Kahvecioglu B, Aström G, Ahlström H, Graf W. Endoanal ultrasound or magnetic resonance imaging for preoperative assessment of anal fistula: a comparative study. Colorectal Dis 2001;3:189-97.

20. Mullen R, Deveraj S, Suttie SA, Matthews AG, Yalamarthi S. MR imaging of fistula in ano: indications and contribution to surgical assessment. Acta Chir Belg 2011;111:393-7.

21. Shafik A. New concept of the anatomy of the anal sphincter mechanism and the physiology of defecation. II. Anatomy of the levator ani muscle with special reference to puborectalis. Invest Urol 1975;13:175-82.

22. Shafik A. A new concept of the anatomy of the anal sphincter 
mechanism and the physiology of defecation. IV. Anatomy of the perianal spaces. Invest Urol 1976;13:424-8.

23. Shafik A. A new concept of the anatomy of the anal sphincter mechanism and the physiology of defecation. VI. The central abscess: a new clinicopathologic entity in the genesis of anorectal suppuration. Dis Colon Rectum 1979;22:336-41.

24. Shafik A. A new concept of the anatomy of the anal sphincter mechanism and the physiology of defecation. III. The longitudinal anal muscle: anatomy and role in anal sphincter mechanism. Invest Urol 1976;13:271-7.

25. Fucini C, Elbetti C, Messerini L. Anatomic plane of separation between external anal sphincter and puborectalis muscle: clinical implications. Dis Colon Rectum 1999;42:374-9.

26. Fröhlich B, Hötzinger $H$, Fritsch $H$. Tomographical anatomy of the pelvis, pelvic floor, and related structures. Clin Anat 1997;10: 223-30.

27. Parks AG, Gordon PH, Hardcastle JD. A classification of fistulain-ano. Br J Surg 1976;63:1-12.

28. Murad-Regadas SM, Regadas Filho FS, Holanda EC, Veras LB,
Vilarinho AD, Lopes MS. Can three-dimensional anorectal ultrasonography be included as a diagnostic tool for the assessment of anal fistula before and after surgical treatment? Arq Gastroenterol 2018;55 (Suppl 1):18-24.

29. van Koperen PJ, Wind J, Bemelman WA, Bakx R, Reitsma JB, Slors JF. Long-term functional outcome and risk factors for recurrence after surgical treatment for low and high perianal fistulas of cryptoglandular origin. Dis Colon Rectum 2008;51:1475-81.

30. Regadas FS, Murad-Regadas SM, Lima DM, Silva FR, Barreto RG, Souza $\mathrm{MH}$, et al. Anal canal anatomy showed by three-dimensional anorectal ultrasonography. Surg Endosc 2007;21:2207-11.

31. Kondylis PD, Shalabi A, Kondylis LA, Reilly JC. Male cryptoglandular fistula surgery outcomes: a retrospective analysis. Am J Surg 2009;197:325-30.

32. Garcés-Albir M, García-Botello SA, Esclapez-Valero P, SanahujaSantafé A, Raga-Vázquez J, Espi-Macías A, et al. Quantifying the extent of fistulotomy: how much sphincter can we safely divide?: a three-dimensional endosonographic study. Int J Colorectal Dis 2012;27:1109-16. 